\title{
OBSERVAÇÕES E ESTIMATIVAS DE PROPRIEDADES TÉRMICAS DO SOLO SOB FLORESTA E PASTAGEM NO LESTE DA AMAZÔNIA
}

\author{
SAULO PRADO DE CARVALHO ${ }^{1}$, JOSÉ RICARDO SANTOS DE SOUZA ${ }^{2}$, MIDORI MAKINO² \\ ${ }^{1}$ Secretaria de Estado de Meio Ambiente, Belém, PA, Brasil \\ ${ }^{2}$ Universidade Federal do Pará, Belém, PA, Brasil \\ spc_meteor@yahoo.com.br,jrssouza@ufpa.br, midori@ufpa.br
}

Recebido Janeiro de 2011 - Aceito Janeiro de 2013

\begin{abstract}
RESUMO
As variações da temperatura e do fluxo de calor em solos sob a floresta nativa de Caxiuanã e uma pastagem natural da Ilha do Marajó, foram monitoradas continuamente no período de dezembro de 2001 a fevereiro de 2005. O objetivo foi comparar as respostas térmicas ao aquecimento diário, dos solos desses dois tipos de ecossistemas existentes no leste da Amazônia, para subsidiar modelos regionais de clima e avaliação dos efeitos de desmatamento. Além das medidas de campo das variáveis acima citadas, em três níveis até a profundidade de $0,5 \mathrm{~m}$, esse trabalho apresenta estimativas de fluxo de calor e propriedades dos solos, tais como: difusividade e condutividade térmicas, profundidade de amortecimento e velocidade de propagação do pulso de aquecimento diário, determinados por métodos analíticos. Os resultados mostraram o contraste sazonal e outras diferenças significativas de respostas entre os dois sítios estudados, destacando o papel do conteúdo de água nos perfis térmicos verticais em cada tipo de solo. $\mathrm{O}$ ajuste obtido entre as medidas e os valores calculados das variáveis, indica a possibilidade de generalização dos resultados para outros sítios de ecossistemas similares na Amazônia.

Palavras-chave: Temperatura do Solo, Propriedades Térmicas, Leste da Amazônia
\end{abstract}

\begin{abstract}
OBSERVATIONS AND ESTIMATES OF THE SOIL THERMAL PROPERTIES UNDER FOREST AND PASTURE COVER ON EAST AMAZONIA.

Temperature and heat flux variations in soils, at sites of the Caxiuanã native forest and a natural pasture in Marajó Island, were continuously monitored in the period between December, 2001 and February, 2005. The objective was to compare the thermal responses to the daily heating, of the soils of these two types of ecosystems present in eastern Amazonia, in order to subsidize regional climate models and the evaluation of deforestation effects. Besides the field measurements of the above mentioned variables, at three levels down to $0.50 \mathrm{~m}$ depth, this work presents estimates of the heat flux and soil properties such as: thermal diffusivity and conductivity, damping depth and propagation speed of the daily heating pulse, determined by analytical methods. The results showed the seasonal contrast and other significant differences between the responses of the two studied sites, especially regarding the role of the water contents on the vertical temperature profiles of each soil type. The observed fitting between the measurements and the computed values of the variables, indicates the possibility of generalization of the results to other similar ecosystems sites in Amazonia.
\end{abstract}

Keywords: Soil Temperature, Thermal Properties, Eastern Amazon.

\section{INTRODUÇÃO}

A busca por informações derivadas da temperatura do solo são fundamentais para um conhecimento detalhado da transferência de calor sob diferentes coberturas vegetais, além de explicar os vários processos químicos, físicos e biológicos nos diversos tipos de ecossistema existentes no planeta (Hillel, 2004). Ademais, a boa representatividade das propriedades térmicas é necessária na interação solo-planta-atmosfera em modelos biogeofísicos em simulações de cenários futuros do clima. Segundo Pielke (2005), a cobertura e uso da terra têm uma importância de primeira ordem como forçante climática. 
Entretanto, o estudo da variabilidade de tal forçante sobre a temperatura, a evaporação, a precipitação e outras variáveis climáticas tem sido ignorado (Pielke, 2005). Simulações de mudanças climáticas feitas por Feddema (2005) com diferentes cenários de paisagem, mostraram que decisões futuras no uso da terra podem alterar as simulações de mudança climática global, que às vezes levam em consideração somente a mudança da composição da atmosfera. No âmbito da Bioquímica, estudos feitos por Almagro et al. (2009) investigaram variações temporais na temperatura e umidade do solo, sob diferentes condições e avaliaram a importância que estas variáveis têm sobre a resposta da respiração do solo. No estudo de Peng et al. (2009) foi mostrada a forte dependência da resposta de $\mathrm{Q}_{10}$ (fator pelo qual a taxa de respiração aumenta a cada $10^{\circ} \mathrm{C}$ de aumento na temperatura do solo) com a profundidade da temperatura do solo medida em diferentes coberturas de vegetação.

Determinações das propriedades térmicas do solo como a condutividade térmica e difusividade térmica, podem ser feitas a partir de medidas diretas avaliando a amostra do solo considerado. Souza et al. (2006) adotaram metodologias laboratoriais para a determinação da difusividade térmica, assim como em Araújo et al. (2004), na obtenção dos valores de condutividade térmica. Por outro lado, autores como Alvalá et al. (2002), Horton e Wierenga (1983) e Antonino et al. (1997) estimaram as difusividades térmicas a partir de temperaturas do solo com uma boa aproximação. No estudo feito por Verhoef et al. (1996), valores de difusividade térmica obtidos por diferentes métodos foram comparados e os resultados mais satisfatórios foram usados para a determinação da condutividade térmica.

Embora se obtenha resultados mais precisos em relação aos métodos analíticos, a determinação de propriedades térmicas no solo por métodos laboratoriais requer custos muito altos. Nesse contexto, a opção por métodos analíticos e estimativas para a determinação das propriedades térmicas do solo é uma boa alternativa, principalmente devido à praticidade em relação aos procedimentos laboratoriais e pelos resultados satisfatórios.

Este artigo tem como objetivo comparar as respostas térmicas em dois sítios experimentais no leste da Amazônia (floresta e pastagem), durante os períodos seco e chuvoso, além de estimar as propriedades térmicas do solo, como a difusividade e condutividade térmica, e calcular o fluxo de calor do solo em um nível intermediário feita a partir de gradientes de temperatura do solo.

\section{MATERIAL E MÉTODOS}

\subsection{Descrição dos sítios experimentais}

Os dados foram coletados nos sítios de floresta em Caxiuanã $\left(01^{\circ} 42^{\prime} 30^{\prime \prime} \mathrm{S}, 51^{\circ} 31^{\prime} 45^{\prime}\right.$ 'W, altitude: $\left.47 \mathrm{~m}\right)$ e de pastagem na Fazenda Araruna( $00^{\circ} 43^{\prime} 25^{\prime}$ S, 48 30' 29” W, altitude: $16 \mathrm{~m}$ ), ambos situados no estado do Pará, na região leste da Amazônia.

A FLONA Caxiuanã, com área de 33.000 hectares, é uma floresta nacional localizada no município de Melgaço-PA. Essa reserva é constituída, em $85 \%$ de sua área, por floresta densa de terra firme, com dossel das árvores maiores a níveis entre 30 e $40 \mathrm{~m}$ de altura; as quais interceptam pouco mais de $10 \%$ da precipitação incidente (Moraes, et al., 1997). O clima da região é caracterizado por uma pluviosidade média anual de $1800 \mathrm{~mm}$, sendo o trimestre mais seco o de setembro a novembro, com precipitações mensais entre 20 e $100 \mathrm{~mm}$, e o mais chuvoso o de fevereiro a abril, com precipitações mensais de 200 a $400 \mathrm{~mm}$ (SUDAM, 1984). O solo do local é Latossolo amarelo distrófico, constituído em sua camada superior de $50 \mathrm{~cm}$ de profundidade por argila arenosa (Lisboa, 1997). Trata-se de solo envelhecido, variando de ácido a fortemente ácido e de boa drenagem, apesar de por vezes apresentar-se bastante argiloso.

A pastagem da fazenda Araruna, localizada no município de Soure-PA é de origem natural, representativa da parte leste da Ilha do Marajó, que é coberta por campos utilizados para criação de gado e búfalo. A vegetação é do tipo cerrado parque, tem-se campos naturais com flora de savana em áreas raramente atingidas pelas inundações. Estes campos são recobertos por vegetação rasteira graminosa de capim barba de bode e arbórea. Os principais solos da região são Plintossolos fase normal, imperfeitamente drenada, fase húmica, Glei Pouco Húmico, solos Aluviais, Areias Quartzosas Hidromórficas, solos Salinos Latossolos Amarelos e Hidromórficos Indiscriminados (IDESP, 1974). A parte oriental da região do Marajó, onde a área de estudo está localizada, apresenta clima tropical quente e úmido com pluviosidade média anual de $2200 \mathrm{~mm}$. No trimestre mais seco (setembro, outubro e novembro - SON), o total médio mensal de precipitação é inferior a $60 \mathrm{~mm}$, enquanto que no trimestre mais chuvoso (janeiro, fevereiro e março - JFM) atinge o total médio de $1400 \mathrm{~mm}$. A precipitação atinge índice máximo em março, quando a Zona de Convergência Intertropical (ZCIT) se centraliza no local.

As observações foram realizadas durante o experimento MILÊNIO-LBA/UFPA, cujas variáveis meteorológicas, temperatura do solo e fluxo de calor no solo, foram monitoradas desde dezembro de 2001 a fevereiro de 2005. Os dados coletados foram separados nos períodos seco e chuvoso, seguindo critério matemático-estatístico proposto por Carvalho (2007). Em termos gerais, o período seco é representado pelos meses de junho a novembro e o período chuvoso pelos meses de dezembro a maio.

Os perfis de temperaturas na floresta e na pastagem foram medidos por sondas de termistores TEMP108 (Campbell Scientific, EUA) nas profundidades de 5,20 e $50 \mathrm{~cm}$, e o fluxo de calor no solo foi registrado por fluxímetros HUKSEFLUX 
HFP01 (Hukseflux, Holanda) em $5 \mathrm{~cm}$ e $20 \mathrm{~cm}$ abaixo da superfície do solo.

\subsection{Teoria das propriedades térmicas do solo}

Para a estimativa das propriedades térmicas do solo, a equação que descreve a transferência uni-dimensional de calor por condução em um meio isotrópico é descrita da seguinte forma:

$$
C \frac{\partial T}{\partial t}=\frac{\partial}{\partial z}\left(\lambda \frac{\partial T}{\partial z}\right)
$$

onde T é a temperatura $\left({ }^{\circ} \mathrm{C}\right), t$ é o tempo $(s), z$ é a profundidade, $C$ é a capacidade calorífica volumétrica $\left(\mathrm{J} \mathrm{m}^{-3}{ }^{\circ} \mathrm{C}^{-1}\right)$ e $\lambda$ é a condutividade térmica $\left(\mathrm{W} \mathrm{m}^{-1}{ }^{\circ} \mathrm{C}^{-1}\right)$.

Considerando que $\mathrm{C}$ e $\lambda$ são independentes do tempo, ou seja, o solo é verticalmente homogêneo em relação às suas propriedades térmicas, a Equação 1 torna-se:

$$
\frac{\partial T}{\partial t}=\alpha \frac{\partial^{2} T}{\partial z^{2}}
$$

onde $\alpha=\frac{\lambda}{C}$ é a difusividade aparente do solo $\left(\mathrm{m}^{2} \mathrm{~s}^{-1}\right)$.

\subsubsection{Difusividade térmica aparente $(\alpha)$}

De acordo com as considerações de isotropia, homogeneidade e ausência de fontes ou sumidouros de calor, onde a temperatura tenha um comportamento periódico na profundidade $z$ e tempo $t$, verifica-se que uma medida da amplitude ou da fase é suficiente para determinar a difusividade térmica. Horton e Wierenga (1983) avaliaram 6 métodos para determinação de $\alpha$ em condições de solo descoberto. Todos os métodos são considerados periódicos e derivam da representação da série de Fourier. No estudo de propriedades térmicas sob solos da Nigéria e Espanha, Verhoef et al. (1996) mostraram que, para uma estimativa adequada de $\alpha$, os métodos da Amplitude e Harmônico foram os que obtiveram melhores resultados.

Para este trabalho, as difusividades aparentes do solo foram determinadas pelo método da amplitude, mostrada a seguir:

$$
\alpha=\frac{\omega}{2}\left(\frac{z_{2}-z_{1}}{\ln \left(A_{1} / A_{2}\right)}\right)^{2}
$$

onde $\omega$ é a frequência angular $\frac{2 \pi}{P}$, sendo $P$ o período do ciclo fundamental, $A_{1}$ é a amplitude em $z_{1}, A_{2}$ é a amplitude em $z_{2}$. Com as três sondas térmicas, foram calculados valores de $\alpha$ na camada $5-20 \mathrm{~cm}$ e $20-50 \mathrm{~cm}$.

\subsubsection{Condutividade térmica do solo $(\lambda)$}

A condutividade térmica do solo foi determinada usando a equação do fluxo vertical de calor no solo:

$$
\phi=-\lambda \frac{\partial T}{\partial z}
$$

onde $\phi$ representa o fluxo de calor no solo $\left(\mathrm{W} \mathrm{m}^{-2}\right), \lambda$ é a condutividade térmica do solo $\left(\mathrm{W} \mathrm{m}^{-1}{ }^{\circ} \mathrm{C}^{-1}\right)$ e $\frac{\partial T}{\partial z}$ é o gradiente térmico de calor na direção z. Como $\phi \mathrm{e} \frac{\partial T}{\partial z}$ são conhecidos, a condutividade térmica foi obtida pelo rearranjamento da Equação 4:

$$
\lambda=-\frac{\phi}{\frac{\partial T}{\partial z}}
$$

\subsubsection{Profundidade de amortecimento (D) e velocidade de propagação (VP)}

A profundidade de amortecimento corresponde à profundidade na qual a amplitude de temperatura é reduzida a 1/e de seu valor à superfície, sendo e $=2,7183$ e é representada pela expressão (Hillel, 2004, Rao et al., 2005):

$$
D=\sqrt{(2 \alpha / \omega)}
$$

A velocidade de propagação da onda da temperatura é obtida através da expressão:

$$
V P=\sqrt{2 \omega \alpha}
$$

\section{RESULTADOS}

\subsection{Regime térmico do solo}

A quantidade de cobertura vegetal exerce influência nas magnitudes médias mensais das temperaturas do solo, com a atenuação dos desvios-padrão (DP) das temperaturas dos solos (Tabela 1). Para comparação podem ser citadas as temperaturas médias em $5 \mathrm{~cm}$ de profundidade na sequencia de diminuição da cobertura vegetal, a saber: $25,3{ }^{\circ} \mathrm{C}$ (floresta), $28,9{ }^{\circ} \mathrm{C}$ (área agrícola) e $30,2{ }^{\circ} \mathrm{C}$ (pastagem). Deste modo, os sítios com cobertura vegetal de grande porte como Caxiuanã apresentaram valores médios de temperatura menores do que $\mathrm{o}$ sítio de Soure, que ostenta uma vegetação de gramíneas . Outro fator de controle das temperaturas é a variabilidade sazonal da precipitação, devido ao movimento latitudinal Norte-Sul da ZCIT.

$\mathrm{Na}$ floresta, a profundidade de $50 \mathrm{~cm}$ esteve mais aquecida de janeiro a novembro em relação às camadas imediatamente superiores, e alcançou um máximo de $25,6^{\circ} \mathrm{C}$ em novembro, enquanto a temperatura mínima foi de $24,8^{\circ} \mathrm{C}$ na camada de $20 \mathrm{~cm}$ em fevereiro. No trimestre Set-Out-Nov, 
Tabela 1 - Valores mensais de temperatura dos solos em 5, 20, e $50 \mathrm{~cm}$ de profundidade para os sítios Caxiuanã, Soure no período de dezembro de 2001 a fevereiro de 2005 .

\begin{tabular}{|c|c|c|c|c|c|c|}
\hline \multicolumn{7}{|c|}{ Temperatura do solo $\left({ }^{\circ} \mathrm{C}\right)$} \\
\hline \multirow[b]{2}{*}{ Mês } & \multicolumn{3}{|c|}{$\begin{array}{c}\text { Floresta } \\
\text { Caxiuanã }\end{array}$} & \multicolumn{3}{|c|}{$\begin{array}{l}\text { Pastagem } \\
\text { Soure }\end{array}$} \\
\hline & $5 \mathrm{~cm}$ & $20 \mathrm{~cm}$ & $50 \mathrm{~cm}$ & $5 \mathrm{~cm}$ & $20 \mathrm{~cm}$ & $50 \mathrm{~cm}$ \\
\hline Jan & 25,41 & 25,44 & 25,49 & 29,09 & 29,16 & 29,91 \\
\hline Fev & 24,87 & 24,81 & 25,05 & 28,11 & 27,94 & 28,45 \\
\hline Mar & 24,88 & 24,86 & 25,10 & 28,65 & 28,43 & 28,76 \\
\hline Abr & 25,18 & 25,17 & 25,35 & 28,85 & 28,55 & 28,86 \\
\hline Mai & 25,45 & 25,42 & 25,53 & 29,14 & 28,80 & 29,05 \\
\hline Jun & 25,18 & 25,19 & 25,39 & 29,21 & 28,94 & 29,21 \\
\hline Jul & 25,24 & 25,20 & 25,35 & 29,15 & 28,88 & 29,18 \\
\hline Ago & 25,40 & 25,37 & 25,43 & 29,68 & 29,32 & 29,51 \\
\hline Set & 25,51 & 25,48 & 25,55 & 31,15 & 30,67 & 30,62 \\
\hline Out & 25,55 & 25,49 & 25,57 & 33,24 & 32,74 & 32,57 \\
\hline Nov & 25,56 & 25,50 & 25,59 & 33,70 & 33,24 & 33,19 \\
\hline Dez & 25,64 & 25,45 & 25,54 & 32,83 & 32,71 & 32,93 \\
\hline Máxima & 25,64 & 25,50 & 25,59 & 33,70 & 33,24 & 33,19 \\
\hline Mínima & 24,87 & 24,81 & 25,05 & 28,11 & 27,94 & 28,45 \\
\hline DP & 0,25 & 0,24 & 0,18 & 1,97 & 1,90 & 1,73 \\
\hline
\end{tabular}

a temperatura em $5 \mathrm{~cm}$ apresentou valores aproximados aos da camada de $50 \mathrm{~cm}$. A temperatura em $20 \mathrm{~cm}$ acompanhou a curva da camada de $5 \mathrm{~cm}$ com valores menores. A floresta apresentou a menor variabilidade em relação à pastagem, com desviospadrão de $0,25^{\circ} \mathrm{C}(5 \mathrm{~cm}), 0,24^{\circ} \mathrm{C}(20 \mathrm{~cm})$ e $0,18^{\circ} \mathrm{C}(50 \mathrm{~cm})$.

No sítio da pastagem, a camada de $5 \mathrm{~cm}$ apresentou temperaturas mais elevadas em relação às profundidades de $20 \mathrm{e}$ $50 \mathrm{~cm}$, em torno de $33,7^{\circ} \mathrm{C}$, no mês de novembro. A temperatura mínima foi de $27,9^{\circ} \mathrm{C}$ em $20 \mathrm{~cm}$ no mês de fevereiro. A pastagem foi o sítio que teve a maior variabilidade da onda de temperatura, com desvios-padrão de $1,97^{\circ} \mathrm{C}(5 \mathrm{~cm}), 1,90^{\circ} \mathrm{C}(20 \mathrm{~cm})$ e 1,73 ${ }^{\circ} \mathrm{C}(50 \mathrm{~cm})$.

Na Figura 1 são mostrados os valores de temperatura do solo nas 3 camadas $(5,20$ e $50 \mathrm{~cm})$ no sítio floresta. A camada de $50 \mathrm{~cm}$ esteve mais aquecida de janeiro a novembro, alcançando um máximo de $25,6{ }^{\circ} \mathrm{C}$ em novembro, mostrando que o fluxo de calor se dirige das camadas mais profundas para as mais superficiais. Em dezembro, a temperatura em $5 \mathrm{~cm}$ se torna mais alta do que as demais, o que garante a entrada de calor para as camadas mais profundas durante este período. A amplitude térmica em torno de $0,6^{\circ} \mathrm{C}$ mostrou que, além da contribuição da intensa cobertura vegetal, a distribuição quase homogênea de chuvas no sítio da floresta atuou como uma barreira da entrada do fluxo de radiação solar incidente, além da própria cobertura das copas das árvores.
O sítio localizado em Soure mostrou uma boa relação entre variabilidade sazonal da precipitação e temperaturas do solo (Figura 2), com elevadas amplitudes sazonais. A pouca cobertura vegetal no local ocasiona um aumento na temperatura do solo nas camadas estudadas. No período chuvoso local, que compreende os meses de dezembro a junho, a temperatura na camada mais profunda fica elevada devido à precipitação que resfria as camadas superiores do solo. A partir de julho até novembro, a situação se inverte com a temperatura em $5 \mathrm{~cm}$, de $33,5^{\circ} \mathrm{C}$, mais quente em relação às temperaturas de 20 e 50 $\mathrm{cm}$, fazendo o fluxo térmico dirigir-se para as camadas mais profundas.

\subsection{Variação diurna da temperatura do solo}

As Figuras 3 e 4 mostram o comportamento diário das temperaturas do solo em 5, 20 e $50 \mathrm{~cm}$ nos dois sítios estudados, separados sazonalmente em período seco e chuvoso e todo o período, que representa o comportamento médio das series temporais. Nas duas figuras pode-se notar a defasagem entre os máximos (ou mínimos) das ondas de temperatura, indicando a propagação diária de calor, tanto para cima, quanto para baixo.

As observações na floresta mostram que, no período seco, as temperaturas dos solos nas profundidades de 20 e 50 $\mathrm{cm}$ foram mais altas do que a temperatura em $5 \mathrm{~cm}$ durante a 


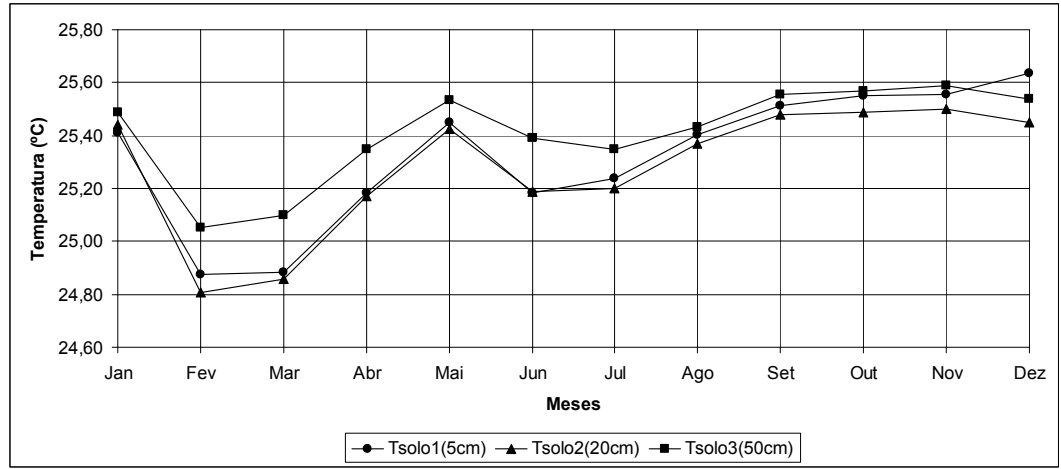

Figura 1 - Média Mensal das Temperaturas do solo em 5, 20 e $50 \mathrm{~cm}$ na Floresta.

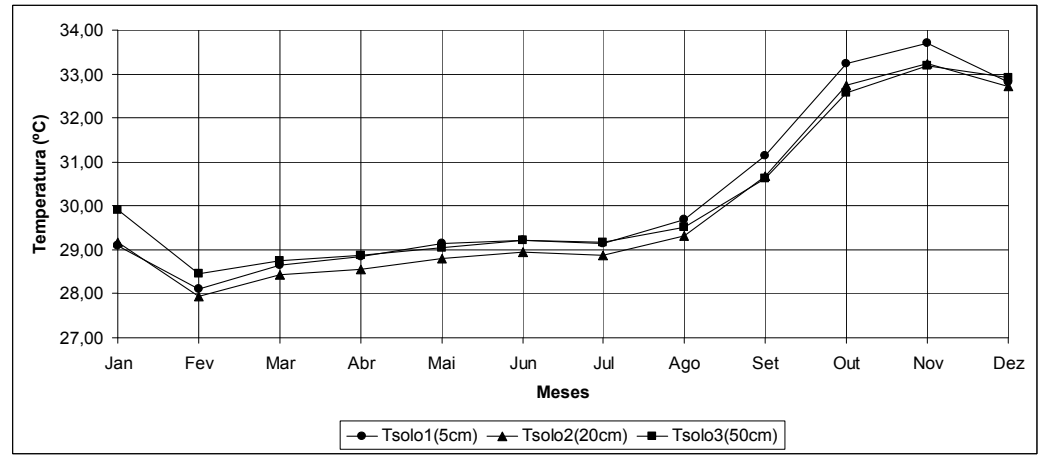

Figura 2 - Média Mensal das Temperaturas do solo em 5, 20 e $50 \mathrm{~cm}$ na Pastagem.
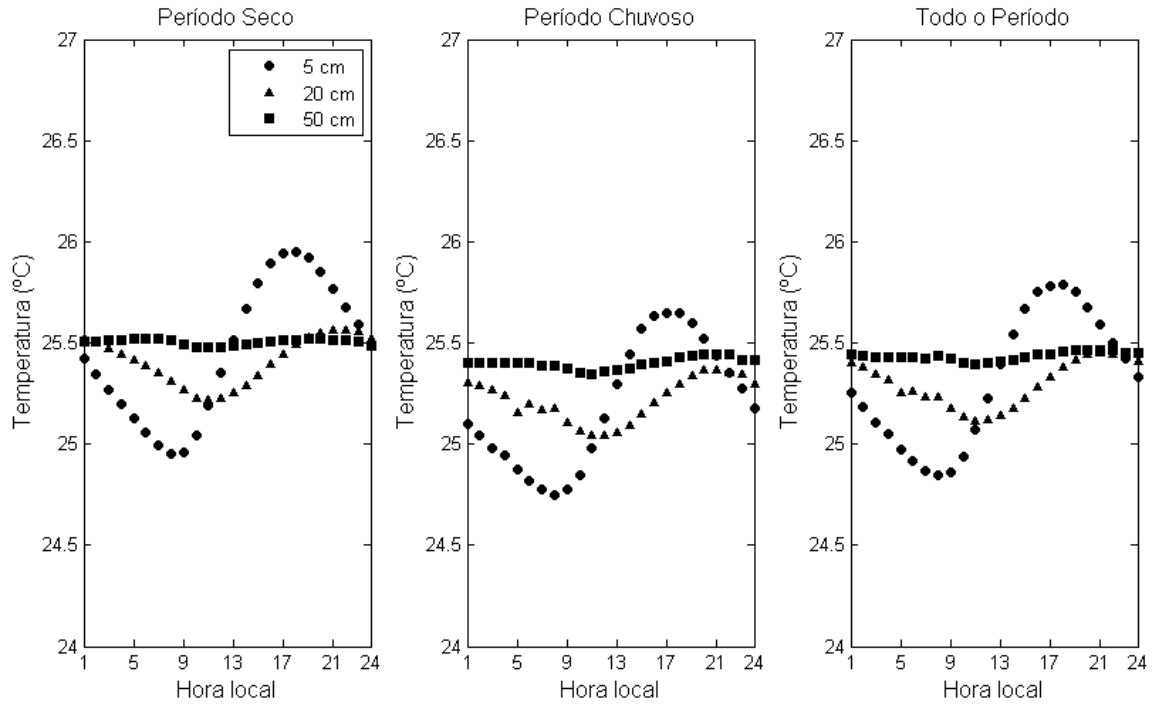

Figura 3 - Temperaturas médias horárias do solo no sítio Floresta nos períodos seco, chuvoso e todo o período.

parte da noite e nas primeiras horas da tarde (de 01:00 h até às 13:00 h local), sendo notado o sentido negativo do fluxo de calor no solo, havendo transferência de calor das camadas mais profundas para as mais superficiais (Figura 4). Quando o fluxo de calor no solo é positivo, entende-se que há transferência de calor da superfície para as camadas mais profundas do solo.
A camada superficial, representada pela temperatura em $5 \mathrm{~cm}$ de profundidade, ficou aquecida nas horas seguintes depois da temperatura máxima de $26^{\circ} \mathrm{C}$ ocorrida às $18: 00 \mathrm{~h}$, sendo observado o sentido positivo do fluxo térmico. Da camada de 5 $\mathrm{cm}$ para $20 \mathrm{~cm}$ foi registrada uma defasagem entre os máximos de temperatura do solo de 3 horas, e desta última para $50 \mathrm{~cm}$, foi 

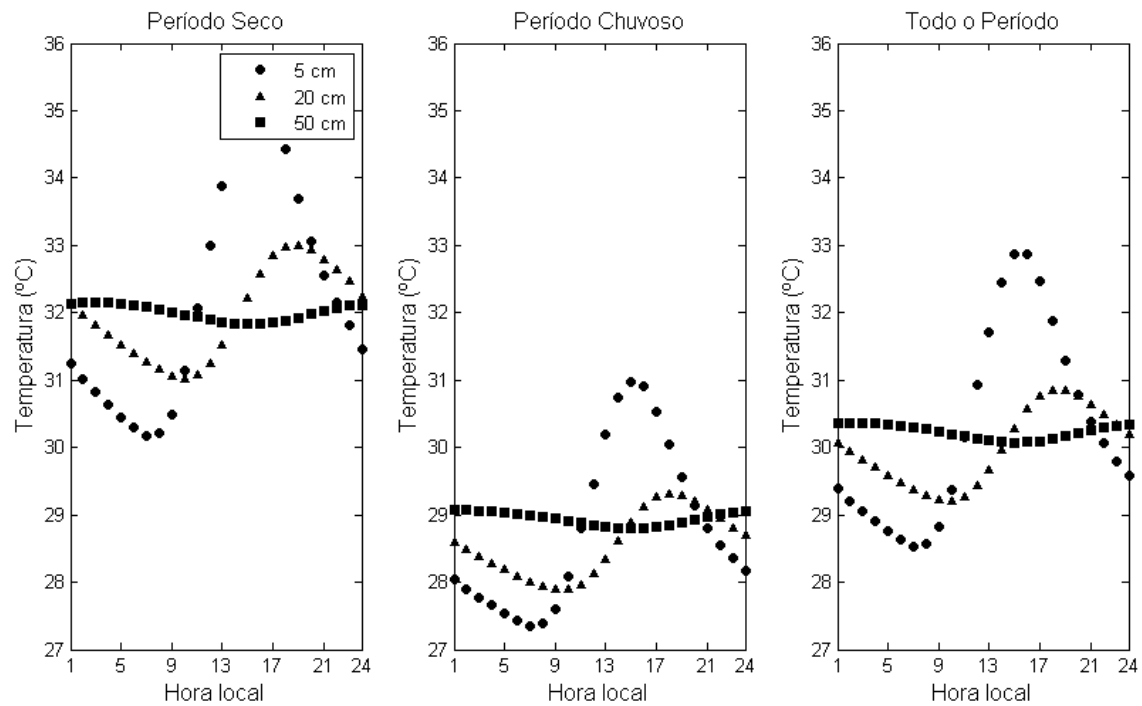

Figura 4 - Temperaturas médias horárias do solo no sítio Pastagem nos períodos seco, chuvoso e todo o período.

observado aproximadamente 7 horas de atraso entre os máximos da temperatura do solo.

No período chuvoso, a temperatura em $50 \mathrm{~cm}$ foi maior do que a temperatura em $20 \mathrm{~cm}$ durante todo o ciclo de 24 horas. Isto indica perda de calor do solo para a atmosfera. Ademais, há uma convergência de calor na camada $20-50 \mathrm{~cm}$ durante 7 horas do dia a partir de 01:00 h local, duas a mais do que no período seco. As amplitudes foram ligeiramente menores do que no período seco, $0,45^{\circ} \mathrm{C}$ em $5 \mathrm{~cm}, 0,16^{\circ} \mathrm{C}$ em $20 \mathrm{~cm}$ e em $50 \mathrm{~cm}$ foi observado um aumento de $0,05^{\circ} \mathrm{C}$. Embora a precipitação se eleve, não houve uma diminuição significativa da temperatura dos solos em relação ao período menos chuvoso (seco).

As baixas temperaturas do solo observadas na floresta com relação aos demais sítios significam que a copa das árvores absorve a maior parte da radiação solar incidente, funcionando como uma primeira superfície, o que deixa o solo em grande parte sombreado.

Na pastagem (Figura 4), também se observa, no período seco, o sentido negativo do fluxo de calor no solo durante a madrugada e parte da manhã (01:00 h até 09:00 h local), e a inversão deste a partir do horário da temperatura máxima de $35,5^{\circ} \mathrm{C}$ em $5 \mathrm{~cm}$ às $16: 00 \mathrm{~h}$, duas horas a menos em relação à floresta. $\mathrm{O}$ atraso entre os máximos de temperatura do solo em $5 \mathrm{~cm}$ e em $20 \mathrm{~cm}$, como na floresta, também foi de 3 horas e de 20 para $50 \mathrm{~cm}$, a defasagem foi de 6 horas.

\subsection{Fluxo de calor no solo}

De uma forma geral, os fluxos de calor sob os solos da floresta, pastagem e da área agrícola não apresentaram variações sazonais de grande amplitude. Porém, apresentaram maiores variações, quando comparados com vegetação e sem vegetação.
A partir desses dados, pode-se obter mais informações importantes sobre o processo de desmatamento.

$\mathrm{Na}$ floresta, os fluxos de calor no solo em $5 \mathrm{~cm}$ e em $20 \mathrm{~cm}$ foram aproximadamente iguais ao longo do dia (Figura 5), exceto no período chuvoso, onde se pode observar um distanciamento entre os fluxos durante à tarde. É mostrado também que os maiores valores de fluxo de calor foram observados no período chuvoso, de aproximadamente $10 \mathrm{~W}$ $\mathrm{m}^{-2}$ às 14:00 h, enquanto que no período seco, o valor máximo foi de $9,3 \mathrm{~W} \mathrm{~m}^{-2}$.

Na pastagem, a amplitude dos fluxos de calor não sofreu diferenças muito significativas entre os períodos seco e chuvoso (Figura 7). A defasagem entre os máximos foi diferente no período seco e chuvoso, sendo 3 horas no primeiro e 2 horas no segundo. Este fato mostra que o alto calor específico da água proveniente da precipitação faz com que o calor se propague com mais eficiência. Outro fato relevante é o valor do fluxo de calor no solo da pastagem atingir um máximo $54 \mathrm{~W} \mathrm{~m}^{-2}$ no período seco, 6 vezes maior em relação à floresta. Contudo, as perdas térmicas alcançam até $20 \mathrm{~W} \mathrm{~m}^{-2}$ durante a noite.

\subsection{Difusividade térmica aparente do solo $(\alpha)$}

Os valores de difusividade térmica aparente (Tabela 2) calculados pelo método da amplitude (Equação 3) foram compatíveis com os valores obtidos por Souza et al. (2006), Alvalá et al. (2002) e Antonino et al. (1997). É observado que a pastagem possui valores maiores de difusividade térmica em relação à floresta na camada de $5-20 \mathrm{~cm}$, tanto no período seco, quanto no chuvoso, com uma média sazonal global de $0,87 \cdot 10^{-6} \mathrm{~m}^{2} \cdot \mathrm{s}^{-1}$ na pastagem e $0,76 \cdot 10^{-6} \mathrm{~m}^{2} \cdot \mathrm{s}^{-1}$ na floresta. $\mathrm{Na}$ 

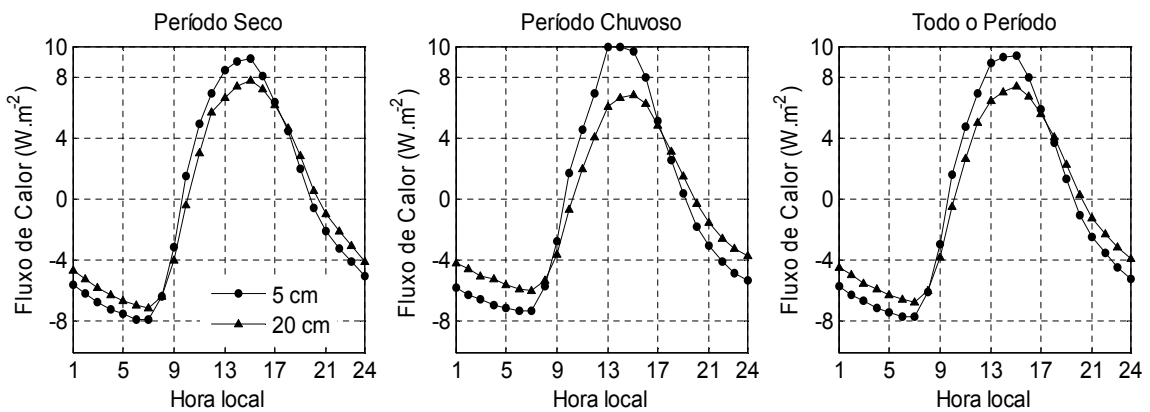

Figura 5 - Evolução diária do fluxo de calor no solo na floresta nos períodos seco, chuvoso e todo o período.
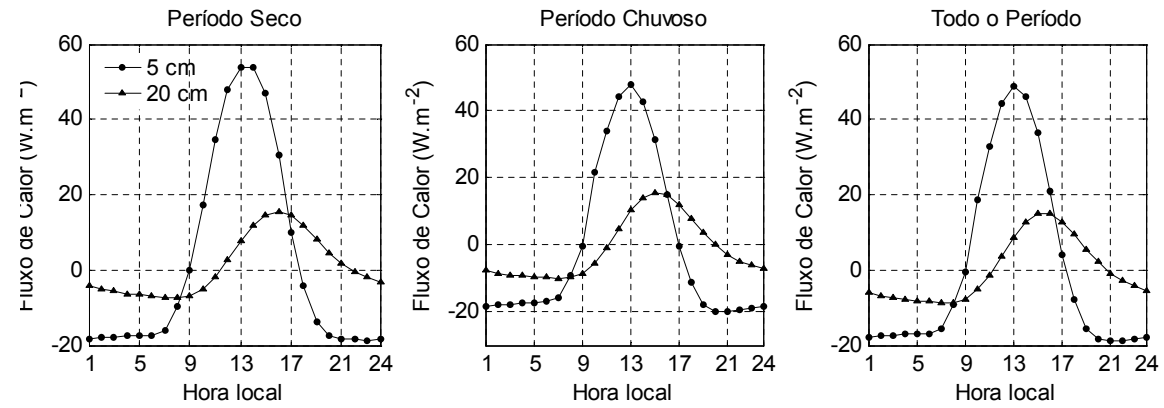

Figura 6 - Evolução diária do fluxo de calor no solo na pastagem nos períodos seco, chuvoso e todo o período.

Tabela 2 - Difusividades térmicas aparentes do solo nos sítios Floresta e Pastagem segundo o métodos da amplitude.

\begin{tabular}{c|c|c|c}
\hline \multicolumn{4}{|c}{ Difusividades $\left(10^{-6} \mathrm{~m}^{2} / \mathrm{s}\right)$} \\
\hline \multirow{3}{*}{ Sítios } & Camadas $(\mathrm{cm})$ & Período Seco & Período Chuvoso \\
\hline \multirow{4}{*}{ Pastagem } & $\mathbf{5 - 2 0}$ & 0,72 & 0,79 \\
\cline { 2 - 4 } & $\mathbf{2 0 - 5 0}$ & 0,80 & 2,28 \\
\cline { 2 - 4 } & $\mathbf{5 - 5 0}$ & 0,73 & 1,49 \\
\hline & $\mathbf{5 - 2 0}$ & 0,81 & 0,93 \\
\cline { 2 - 4 } & $\mathbf{2 0 - 5 0}$ & 0,96 & 1,22 \\
\cline { 2 - 4 } & $\mathbf{5 - 5 0}$ & 0,91 & 1,11 \\
\hline
\end{tabular}

camada 20-50 cm, os maiores valores de difusividade foram encontrados na floresta, com um valor médio de difusividade de $3,6 \cdot 10^{-6} \mathrm{~m}^{2} \cdot \mathrm{s}^{-1}$ e $3,1 \cdot 10^{-6} \mathrm{~m}^{2} \cdot \mathrm{s}^{-1}$ da pastagem durante todo o período analisado. Esses resultados confirmam o fato que a difusividade térmica aparente é altamente heterogênea ao longo do perfil de solo, devido principalmente à presença de água, que aumenta a capacidade calorífica e a condutividade térmica do solo, diretamente associados à difusividade térmica.

\subsection{Profundidade de amortecimento (D) e velocidade de propagação (VP)}

A Tabela 3 mostra os valores da profundidade de amortecimento calculados nos dois sítios no período seco
Tabela 3 - Valores da Profundidade de amortecimento (D) no sítio floresta e pastagem.

\begin{tabular}{c|c|c|c}
\hline Sítios & Camadas $(\mathrm{cm})$ & Período Seco & Período Chuvoso \\
\hline \multirow{5}{*}{ Floresta } & $\mathbf{5 - 2 0}$ & 14 & 15 \\
\cline { 3 - 4 } & $\mathbf{2 0 - 5 0}$ & 15 & 25 \\
\cline { 3 - 4 } & $\mathbf{5 - 5 0}$ & 15 & 20 \\
\hline \multirow{5}{*}{ Pastagem } & $\mathbf{5 - 2 0}$ & 15 & 16 \\
\cline { 3 - 4 } & $\mathbf{2 0 - 5 0}$ & 16 & 18 \\
\cline { 3 - 4 } & $\mathbf{5 - 5 0}$ & 16 & 18 \\
\hline
\end{tabular}

e chuvoso nas camadas $5-20 \mathrm{~cm}, 20-50 \mathrm{~cm}$ e $5-50 \mathrm{~cm}$. No período seco, as profundidades de amortecimento calculadas na camada 5-20 cm foram $14 \mathrm{~cm}$ no sítio Floresta e $15 \mathrm{~cm}$ no sítio Pastagem. Na camada $5-50 \mathrm{~cm}$, foram encontrados valores de $15 \mathrm{~cm}$ na Floresta e $16 \mathrm{~cm}$ na Pastagem. No período chuvoso, as profundidades de amortecimento na camada superficial $(5-20 \mathrm{~cm})$ na Floresta e Pastagem foram $15 \mathrm{~cm}$ e 16 $\mathrm{cm}$, respectivamente. $\mathrm{Na}$ camada $20-50 \mathrm{~cm}$, foram calculadas profundidades de $25 \mathrm{~cm}$ na Floresta e $15 \mathrm{~cm}$ na pastagem.

A Tabela 4 mostra a velocidade com que o calor penetra no solo dos dois sítios. É observado na camada rasa $(5-20 \mathrm{~cm})$, nos períodos seco e chuvoso, que a velocidade de propagação apresentou uma diferença de $3 \mathrm{~cm} / \mathrm{h}$, sendo $36,79 \mathrm{~cm} / \mathrm{h}$ na Floresta e 39,09 cm/h na Pastagem, na época menos chuvosa, e $38,51 \mathrm{~cm} / \mathrm{h}$ na Floresta e $41,9 \mathrm{~cm} / \mathrm{h}$ na Pastagem no período 
Tabela 4 - Valores da Velocidade de Propagação (VP) nos sítios Floresta e Pastagem. Velocidade de propagação $(\mathrm{cm} / \mathrm{h})$.

\begin{tabular}{c|c|c|c}
\hline Sítios & Camadas $(\mathrm{cm})$ & Período Seco & Período Chuvoso \\
\hline \multirow{4}{*}{ Floresta } & $\mathbf{5 - 2 0}$ & 36,79 & 38,51 \\
\cline { 3 - 4 } & $\mathbf{2 0 - 5 0}$ & 38,91 & 65,49 \\
\cline { 3 - 4 } & $\mathbf{5 - 5 0}$ & 38,18 & 53,09 \\
\hline \multirow{5}{*}{ Pastagem } & $\mathbf{5 - 2 0}$ & 39,09 & 41,9 \\
\cline { 3 - 4 } & $\mathbf{2 0 - 5 0}$ & 42,61 & 47,98 \\
\cline { 3 - 4 } & $\mathbf{5 - 5 0}$ & 41,37 & 45,77 \\
\hline
\end{tabular}

das chuvas. Comparando a camada de $20-50 \mathrm{~cm}$, as velocidades calculadas foram: $38,91 \mathrm{~cm} / \mathrm{h}$ na Floresta e $42,61 \mathrm{~cm} / \mathrm{h}$ na Pastagem durante o período seco e no período chuvoso foi de $65,49 \mathrm{~cm} / \mathrm{h}$ na floresta e $47,98 \mathrm{~cm} / \mathrm{h}$ na Pastagem, sendo constatada uma diferença de $17 \mathrm{~cm} / \mathrm{h}$. Na camada $5-50 \mathrm{~cm}$, a VP na Floresta foi $38,18 \mathrm{~cm} / \mathrm{h}$ e na Pastagem, $41,37 \mathrm{~cm} / \mathrm{h}$ e durante o período chuvoso foram calculadas de VP de $53,09 \mathrm{~cm} / \mathrm{h}$ na Floresta e 45,77 cm/h na Pastagem.

\subsection{Condutividades térmicas calculadas}

A Tabela 5 apresenta as condutividades térmicas calculadas na camada $5-20 \mathrm{~cm}$ de acordo com a Equação 5 . Considerado $1 \mathrm{~W} \mathrm{~m}^{-1}{ }^{\circ} \mathrm{C}^{-1}$ como unidade de condutividade (UC), O sítio Floresta apresentou uma variação significativa de condutividade térmica, sendo 1,51 UC no período seco e 3,31 UC no período chuvoso. O sítio pastagem apresentou pouca diferença na condutividade, sendo 0,67 UC no período seco e 0,62 UC no período chuvoso.

Os valores de difusividade térmica aparente e condutividade térmica do solo se aproximaram dos resultados encontrados no trabalho de Souza et al. (2006), que determinaram propriedades térmicas através de métodos laboratoriais.
Tabela 5 - Condutividades térmicas calculadas $\left(\mathrm{W} \mathrm{m}-1{ }^{\circ} \mathrm{C}-1\right)$ nos sítios Floresta e Pastagem.

\begin{tabular}{c|c|c|c}
\hline Sítios & Camadas (cm) & Período Seco & Período Chuvoso \\
\hline Floresta & $\mathbf{5 - 2 0}$ & 1,51 & 3,31 \\
\hline Pastagem & $\mathbf{5 - 2 0}$ & 0,67 & 0,62 \\
\hline
\end{tabular}

\subsection{Cálculo do fluxo de calor no solo}

Com a determinação da condutividade térmica do solo e o gradiente de temperatura, foi possível calcular o fluxo de calor no solo na camada 5-20 cm a partir da Equação 4. As Figuras 7 e 8 mostram os fluxos de calor no solo, medidos em $5 \mathrm{~cm}$ e $20 \mathrm{~cm}$, e calculados na profundidade intermediária $(12,5$ $\mathrm{cm})$. O comportamento da condutividade térmica calculada foi compatível, principalmente no sítio pastagem (Figura 7), que foi semelhante, tanto no período seco, quanto no chuvoso. No caso do sítio Floresta (Figura 8), a complexidade do comportamento da condutividade é atribuída à estrutura das árvores que, além da notada redução de temperatura do alto do dossel até o solo, retarda os efeitos da onda de calor nas profundidades estudadas. Os maiores valores de fluxo de calor no solo foram registrados na pastagem, chegando a $55 \mathrm{~W} \mathrm{~m}^{-2}$ durante o período seco na profundidade de $5 \mathrm{~cm}$. O menor fluxo de calor no solo registrado foi $-9 \mathrm{~W} \mathrm{~m}^{-2}$ no sítio floresta durante o período chuvoso.

\section{CONCLUSÃO}

Numa breve avaliação da temperatura do solo nos ecossistemas estudados, pôde ser constatado que essa variável possui um comportamento bastante distinto, sobretudo quando se compara o sítio floresta em relação à pastagem. Deste modo, o sítio com considerável cobertura vegetal, como Caxiuanã, apresentou menor variação diurna das temperaturas do solo do que os sítios Soure, que ostentam uma vegetação menos vigorosa. Outro fator de controle das temperaturas do solo é
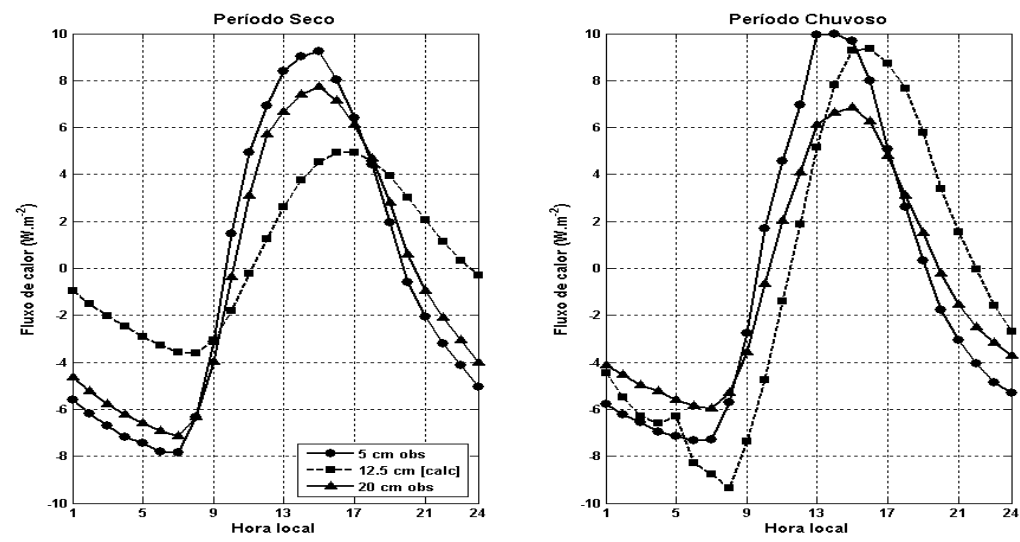

Figura 7 - Fluxo de calor no solo observado (linha contínua) e calculado (linha tracejada) no sítio Floresta. 

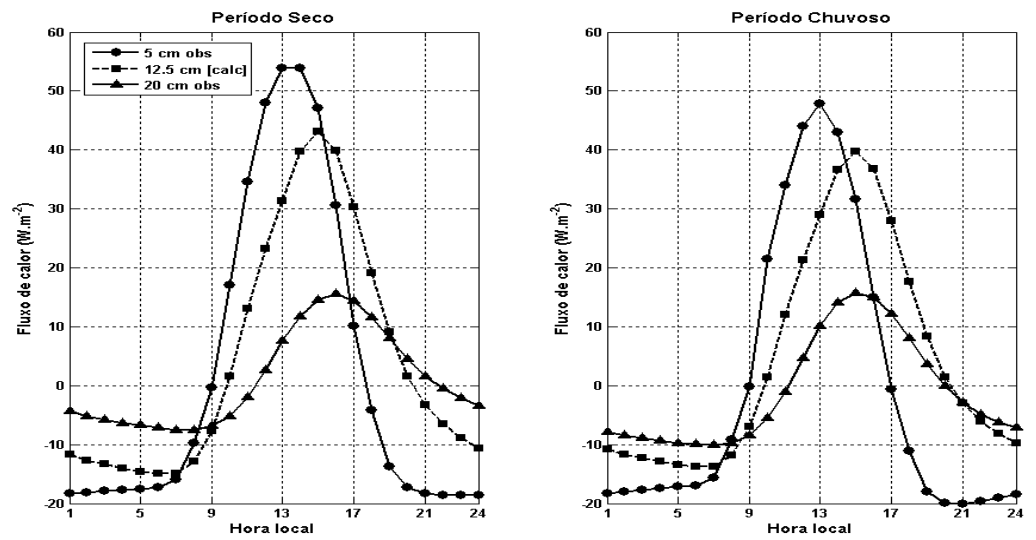

Figura 8 - Fluxo de calor no solo observado (linha contínua) e calculado (linha tracejada) no sítio Pastagem.

a variabilidade sazonal da precipitação, devido ao movimento meridional da Zona de Convergência Intertropical. O périodo Chuvoso nos dois sítios foi diferente no período estudado. Choveu mais no sítio pastagem do que no sítio floresta. Este último, devido à sua estrutura de vegetação, favoreceu um maior armazenamento de água no solo.

As propriedades térmicas do solo, tais como, difusividade térmica, condutividade térmica, profundidade de amortecimento e velocidade de propagação variaram entre as profundidades e sazonalidade. A vegetação e a água no solo durante o período chuvoso foram determinantes na dinâmica da propagação do calor da superfície para a camada mais profunda no solo. Os resultados encontrados neste trabalho foram compatíveis aos trabalhos de Alvalá et. al. (2002) e Souza et. al. (2006), embora as propriedades térmicas fossem determinadas em laboratório. Assim como visto nos trabalhos de Horton e Wierenga (1983), Antonino et al. (1997) e Verhoef et al. (1996), as propriedades térmicas do solo podem ser encontradas analiticamente com aproximação aceitável.

\section{AGRADECIMENTOS}

Agradecemos à Professora Júlia Clarinda Paiva Cohen (UFPA), pelo apoio estrutural dispensado ao desenvolvimento deste trabalho, desde sua concepção. Também agradecemos aos revisores e editores pelas orientações e críticas positivas, as quais ajudaram na clareza desse artigo.

\section{REFERÊNCIAS}

ALMAGRO, M., LOPÉZ, J., QUEREJETA, J. I., MARTINEZMENA, M. Temperature dependence of soil $\mathrm{CO}_{2}$ efflux is strongly modulated by seasonal patterns of moisture availability in a Mediterranean Ecossystem. Soil Biology and Biochemistry. v. 41, n. 3, p. 594-605, 2009.
ALVALÁ, R. C. S.; et al. Intradiurnal and seasonal variability of soil temperature, heat flux, soil moisture content, and thermal properties under forest and pasture in Rondônia. Journal of Geophysical Research - Atmospheres, v. 107, p. 10-1-10-20. 2002.

ANTONINO, A. C. D., LIRA, C. A. B. O., DALL'OLIO, A., AUDRY, P., PINTO, A. X. M. Influência do posicionamento de sondas térmicas na determinação da difusividade térmica e do fluxo de calor no solo em condições de campo. Revista Brasileira de Ciência do Solo, v. 21, p. 165-172. 1997.

ARAÚJO, R. L. C. et al. Influência Ambiental sobre a Estrutura Geotermal Rasa. Revista brasileira de Geofísica, v. 22, n. 1, p. 33-44. 2004.

FEDDEMA, J. J. The Importance of land-cover change in simulating future climates. Science, v. 310, p. 1674-1676, 2005.

HILLEL, D. Introduction to environmental soil physics. San Diego Elsevier/Acad. Press, 2004. 494 p.

CARVALHO, S. P. Regimes Térmico e Hídrico em Solos sob Ecossistemas naturais e área Agrícola no Leste da Amazônia. 2007. 88 f. Dissertação (Mestrado em Ciências Ambientais). UFPA. Belém, 2007.

HORTON, R.; WIERENGA, P. J., Evaluation of methods for determining the apparent thermal diffusivity of soil near the surface. Soil Science Society of America Journal, Madison, v. 47 , p. 25-32, 1983.

IDESP. Estudo integrado da Ilha do Marajó. Belém, 1974. $333 p$.

LISBOA, P. L. B. (org). Caxiuanã. Belém: CNPq/Museu Paraense Emílio Goeldi, 1997. 150 p.

MORAES , J. C.; COSTA, J. de P. R.; ROCHA, E. J. P. e SILVA, I. M. O. Estudos hidrometeorológicos na Bacia do rio Caxiuanã. In: LISBOA, P. L. B. (org). Caxiuanã. Belém: CNPq/Museu Paraense Emílio Goeldi, 1997, p. 85-95. 
PENG, S., PIAO, S., WANG, T., SUN, J., SHEN, ZEHAO, S. Temperature sensivity of soil respiration in different ecosystems in China. Soil Biology and Biochemistry. v. 41, n. 5, 1008-1014, 2009.

PIELKE, R. A. Land Use and Climate Change. Science, v 310, p. 1625-1626, 2005.

RAO, T. V. R, SILVA, B. B., MOREIRA, A. A. Características térmicas do solo em Salvador-BA. Revista Brasileira de Engenharia Agrícola e Ambiental, v. 9, n. 4, p. 554-559, 2005.

SOUZA, J. R. S., MAKINO, M., ARAÚJO, R. L. C., COHEN, J. C. P., PINHEIRO, F. M. A. Thermal properties and heat fluxes in soils under Forest and pasture, in Marabá, PA, Brazil. Revista Brasileira de Meteorologia, v. 21, n. $3^{\text {a }}$, 89-103, 2006.
SUPERINTENDÊNCIA DO DESENVOLVIMENTO DA AMAZÔNIA (SUDAM). Projeto de hidrologia e Climatologia da Amazônia (SUDAM/PHCA). Atlas climatológico da Amazônia Brasileira. Belém, 1984.

VERHOEF, A., van den HURK, B. J. J. M., JACOBS, A. F. G., HEUSINKFELD, B. G. Thermal soil properties for vineyard (EFEDA-I) and savanna (HAPEX-Sahel) sites. Agricultural and Forestry Meteorology, v. 78, p. 1-18. 1996. 